\title{
Potential for spread of the white-nose fungus (Pseudogymnoascus destructans) in the Americas: use of Maxent and NicheA to assure strict model transference
}

\author{
Luis E. Escobar ${ }^{1,2}$, Andrés Lira-Noriega ${ }^{3}$, Gonzalo Medina-Vogel ${ }^{1}$, A. Townsend Peterson ${ }^{3}$ \\ ${ }^{1}$ Facultad de Ecología y Recursos Naturales, Universidad Andres Bello, Santiago, Chile; ${ }^{2}$ Center for Global \\ Health and Translational Science, State University of New York Upstate Medical University, Syracuse, USA; \\ ${ }^{3}$ Biodiversity Institute, University of Kansas, Lawrence, USA
}

\begin{abstract}
Emerging infectious diseases can present serious threats to wildlife, even to the point of causing extinction. Whitenose fungus (Pseudogymnoascus destructans) is causing an epizootic in bats that is expanding rapidly, both geographically and taxonomically. Little is known of the ecology and distributional potential of this intercontinental pathogen. We address this gap via ecological niche models that characterise coarse resolution niche differences between fungus populations on different continents, identifying areas potentially vulnerable to infection in South America. Here we explore a novel approach to identifying areas of potential distribution across novel geographic regions that avoids perilious extrapolation into novel environments. European and North American fungus populations show differential use of environmental space, but rather than niche differentiation, we find that changes are best attributed to climatic differences between the two continents. Suitable areas for spread of the pathogen were identified across southern South America; however caution should be taken to avoid underestimating the potential for spread of this pathogen in South America.
\end{abstract}

Keywords: white nose fungus, Pseudogymnoascus destructans, spatial epidemiology, ecological niche, bats, Maxent, NicheA.

\section{Introduction}

Besides habitat loss and pollution, emerging infectious diseases can present serious threats to wildlife. The fungus Pseudogymnoascus destructans (also called Geomyces destructans) is related to saprophytic coldgrowing species but produces cutaneous infections in bats (Blehert et al., 2009; Minnis and Lindner, 2013). Evidence of this new disease was established in North American in early 2006; infected bats displayed a white fungal growth in mouth, muzzle, ears and wings (Blehert et al., 2009). At fine scales, disease caused by P. destructans can be considered density-dependent or frequencydependent according to the species involved (Langwig et al., 2012); across broader regions, it is density-dependent (Maher et al., 2012; Thogmartin et al., 2012), causing the white-nose syndrome (WNS) in native bat populations in North America (Lorch et al., 2011).

WNS is associated with drastic bat population declines across eastern North America, with a mean

\footnotetext{
Corresponding author:

Luis E. Escobar

Center for Global Health and Translational Science

State University of New York, Upstate Medical University

750 East Adam Street, Syracuse, New York 13210, USA

Tel. +1 315 464-8153; Fax +1 315 464-4417

E-mail: ecoguate2003@gmail.com
}

mortality of $73 \%$ (range $30-99 \%$ ) in infected colonies (Frick et al., 2010). Nine bat species have been found to be susceptible for infection by the fungus (Turner et al., 2011); species exhibiting the most dramatic population declines are the tri-coloured bat (Perimyotis subflavus), the long-eared myotis (Myotis septentrionalis), the little brown myotis (M.lucifugus) and the Indiana myotis (M. solidalis); the latter two are at risk of extinction based on their rates of decline caused by WNS (Langwig et al., 2012). To date, the fungus is estimated to have killed $>5.5$ million bats in North America (National Park Service, 2013). Optimal growth of fungus isolates occurs at $5-10{ }^{\circ} \mathrm{C}$, with a maximum of $20^{\circ} \mathrm{C}$ (Blehert et al., 2009), similar to the microclimatic conditions found in caves; however, as landscape and climate contexts influence microclimatic conditions inside caves (Badino, 2004; Perry, 2013), a recent report found that WNS mortality in North America correlate with climate and landscape variables (Flory et al., 2012).

The fungus has been confirmed in the north-eastern part of the United States of America (USA) (Maher et al., 2012; National Park Service, 2013) and southeastern Canada (Turner et al., 2011). Evidence suggests that the pathogen is native to Europe (Wibbelt et al., 2010), where it is showing increasing incidence (Martínková et al., 2010) and some evidence of spread (Martínková et al., 2010; Puechmaille et al., 
2010b; Wibbelt et al., 2010): its translocation to the Americas was apparently via anthropogenic activity (Frick et al., 2010). A major unknown is the degree to which other sectors of the Americas are susceptible to this pathogen (Fenton, 2012), an important matter in light of its broad spread to date of $>2,220 \mathrm{~km}$ from where the epizootic initiated (Maher et al., 2012). For concerns of both biodiversity conservation and ecosystem benefits of bats (Kunz et al., 2011), we address two questions: (i) do ecological differences in abiotic factors (i.e. climate) at coarse resolutions exist between $P$. destructans populations in North America and Europe?; and (ii) what is the potential for invasion by $P$. destructans into temperate South America? Answers to these questions will aid the understanding of how and why P. destructans has spread (emerged) so successfully as well as contribute to estimating its potential to become established in yet other regions.

\section{Materials and methods}

\section{Occurrence of infection}

We obtained centroids of polygons (i.e. county or district) in Canada and USA, reported as WNS-positive by the U.S. Geological Survey (USGS, 2013) during January 2007 to May 2013, as coordinates of occurrence of sites representing areas where $P$. destructans is present. In light of known, relatively broad bat movements (Kurta and Murray, 2002; Thogmartin et al., 2012) and relatively uniform size of counties across eastern North America, where the epizootic has reached so far (Peterson, 2008), basing analysis on county centroids is a robust approach. $P$. destructans occurrences in Europe were obtained through locations listed in published scientific articles, but only taking into account locations with species diagnoses based on molecular analyses. In the case multiple occurrences fell in single pixels with respect to the environmental variables, we reduced the number of occurrences to one single occurrence per grid cell.

\section{Environmental variables}

We used 15 climatic variables (Hijmans et al., 2005) in analyses at $\sim 1.8-\mathrm{km}$ resolution, excluding the four layers that combine precipitation and temperature information into the same layer (Table 1), since they show odd spatial anomalies in the form of odd discontinuities between neighbouring pixels. We reduced the dimensionality of the climatic layers via principal components analysis in ArcGIS 9.3 (ESRI; Redlands, USA) retaining 11 components with eigenvalues $>1$, which summarises $>99.9 \%$ of total environmental variance across the study region.

\section{Study area}

The dispersal capacity of P. destructans is hard to estimate considering its rapid expansion in recent years (Hallam and Mccracken, 2010), but these considerations are crucial because the geographical extent

Table 1. Variables considered in the study.

\begin{tabular}{|c|c|}
\hline Included & Excluded \\
\hline Annual mean temperature & Mean temperature of wettest quarter \\
\hline Mean diurnal range & Mean temperature of driest quarter \\
\hline \multicolumn{2}{|l|}{ Isothermality } \\
\hline \multicolumn{2}{|l|}{ Temperature seasonality } \\
\hline \multicolumn{2}{|c|}{ Maximum temperature of warmest month } \\
\hline \multicolumn{2}{|c|}{ Minimum temperature of coldest month } \\
\hline \multicolumn{2}{|l|}{ Temperature annual range } \\
\hline \multicolumn{2}{|c|}{ Mean temperatures of warmest quarters } \\
\hline \multicolumn{2}{|c|}{ Mean temperatures of coldest quarters } \\
\hline Annual precipitation & Precipitation of warmest quarter \\
\hline Precipitation of wettest month & Precipitation of coldest quarter \\
\hline \multicolumn{2}{|l|}{ Precipitation of driest month } \\
\hline \multicolumn{2}{|l|}{ Precipitation seasonality } \\
\hline \multicolumn{2}{|l|}{ Precipitation of wettest quarter } \\
\hline Precipitation of the driest quarter & \\
\hline
\end{tabular}




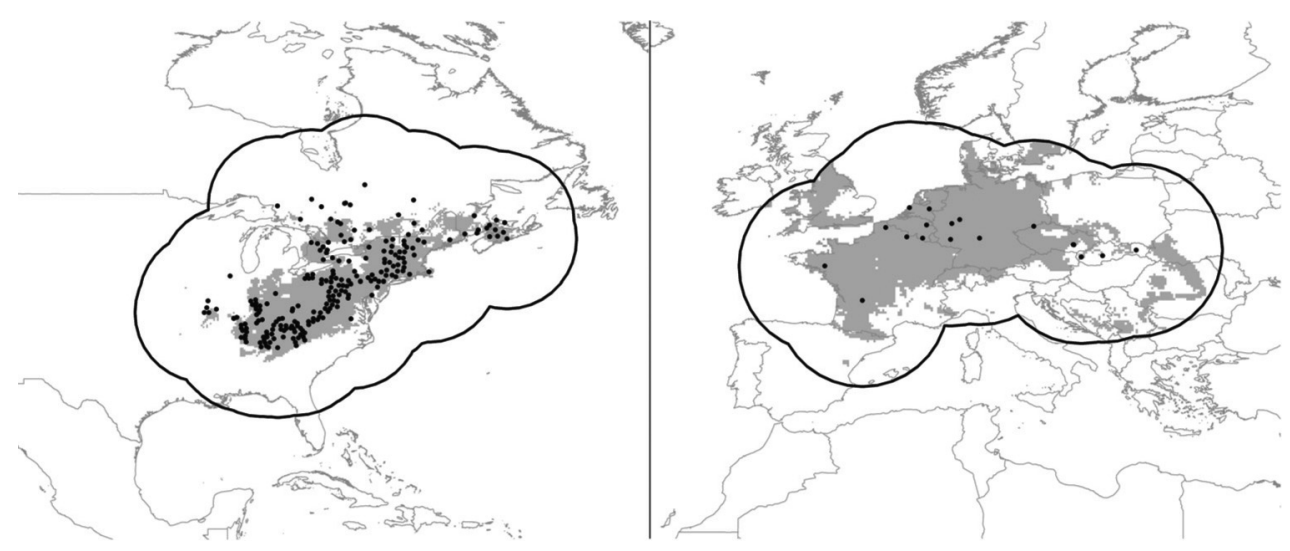

Fig. 1. Potential distribution and occurrence of Pseudogymnoascus destructans in Europe and North America. Delimitation of study areas with potential distribution of $P$. destructans (gray) and actual occurrences (points).

of the analysis $(\mathrm{M})$ has important effects on outcomes of ecological niche modelling exercises (Barve et al., 2011). We used a buffer distance of $500 \mathrm{~km}$ around European and North American occurrences (M; Fig. 1 ), as this distance has been observed yearly from one infected county to the next (Maher et al., 2012); all analyses were carried out within the areas delimited by these buffers. We generated ecological niche models independently for North America and Europe and also for the two continents pooled.

We also explored the potential distribution of P. destructans in Latin America. Considering that the current distribution of $P$. destructans in North America and Europe is entirely north of latitude $23.5^{\circ} \mathrm{N}$ (the Tropic of Cancer). In order to avoid projection onto entirely novel conditions (Elith et al., 2010; Owens et al., 2013), we explored the invasive potential of the agent in continental areas south of latitude $23.5^{\circ} \mathrm{S}$ (the Tropic of Capricorn) including portions of Argentina, Brazil, Chile, Paraguay, and Uruguay. We developed and explored six maps representing the following niche model projections: North America, Europe, North America and Europe pooled, North America projected to South America, Europe projected to South America and North America and Europe pooled projected to South America.

\section{Niche models}

Niche models were developed using Maxent 3.3.3.k (Phillips et al., 2006); specific settings were bootstrap with 100 replicates, $20 \%$ test points and a random seed. To generate binary maps, we chose the minimum threshold that includes $90 \%$ of training occurrence data (Peterson et al., 2007b, 2011). Environments identified via Maxent modelling were projected and explored in geographical space. NicheA, version 1.2
(Qiao et al., 2013) was used to explore the shape, size and position of clouds of known occurrences, niches derived from Maxent analyses and conditions available in multidimensional environmental spaces; the programme also allows users to extrapolate ecological niches through minimum-volume ellipsoids around Maxent prediction (Qiao et al., 2013). To visualise niches in environmental space using NicheA, we displayed the first three principal components derived from the climatic layers from across the union of the North America and Europe study areas, which summarised $>95 \%$ of total environmental variance in a simple, three-dimensional space and then plotted niche models against this background.

Considering that environments from distinct geographical regions do not present identical sets of environmental conditions, we used background similarity tests to assess niche differentiation between $P$. destructans populations in Europe and North America, testing whether the two niche clouds are more similar than expected by chance (Warren et al., 2010), given areas (and conditions) accessible to each (Barve et al., 2011). We calculated environmental similarity of $P$. destructans between the northern continents using the D and I statistics, calculated using ENMTools version 1.3 (Warren et al., 2008). Both indexes range from 0 (no overlap in environmental use) to 1 (complete overlap in environmental use). For the background similarity test, we developed 100 replicate comparisons of each population's known occurrences against the background (points drawn from the accessible area) of the other (sample sizes matching those available for the "background" population), thresholded all models using $\mathrm{E}=10 \%$ (Pearson et al., 2007) and compared observed similarities (i.e. between models based on actual occurrences) with replicate observed-background distributions. 


\section{Niche projections}

Models calibrated using Maxent with information from North America and Europe were projected to South America through three different approaches using:

(i) Maxent without extrapolation and clamping for simple model transfer;

(ii) Maxent with extrapolation and clamping for projections; and

(iii) NicheA to generate minimum-volume ellipsoids enclosing the same replicate training data sets that were generated in Maxent.

We used these minimum-volume ellipsoids under the assumption that fundamental ecological niches should be be convex taking the general form of ellipsoids (Soberón and Nakamura, 2009). Projecting Maxent models using NicheA indentifies environments falling inside ellipsoids representative of species' niches under some circumstances providing biologically-realistic transfers, even when environments differ from those in the calibration area (Owens et al., 2013; Qiao et al., 2013). Models were transferred to geographical space to explore potential suitable areas for P. destructans in South America. Binary maps from projections of Maxent and NicheA were generated using a threshold of $E=10 \%$ of training occurrence data (Peterson et al., 2011). Similarity to environments between calibration areas and novel areas for projection (e.g. South America) was assessed using mobility-oriented parity (MOP) according to Owens et al. (2013), which refines the earlier multivariate environmental similarity surface (MESS) metrics implemented within Maxent for identifying areas of simple transfer (i.e. interpretation is acceptable) versus areas where extrapolation is occurring and interpretation should involve considerable caution (Elith et al., 2010).

Fungus potential distribution and richness of bat populations

P. destructans is known to affect numerous bat species (Blehert et al., 2009), which makes it crucial to understand bat distributional patterns in relation to the potential distribution of the fungus. We assembled extent-of-occurrence maps for all bat species occurring in South America south of $23.5^{\circ} \mathrm{S}$ from online sources (International Union for Conservation of Nature, IUCN, 2012), which were converted to raster formats and summed in ArcGIS version 9.3 to create maps approximating bat species richness patterns.
Results

In total, we obtained 218 confirmed WNS occurrences from North America and 20 from Europe (Martínková et al., 2010; Puechmaille et al., 2010, 2011b). These occurrences were resampled into 218 grid cells in North America and 18 in Europe (Fig. 1).

Models for Europe and North America were used to estimate potential distributional areas on each continent (Fig. 1). Background similarity tests comparing niches of the fungus in North America and Europe indicated that amounts of environmental overlap fell within null expectations, i.e. the hypothesis of niche similarity could not be rejected $(\mathrm{P}>0.05)$ given similarity or difference in the environmental backgrounds of the two continental study areas. This result suggests that ecological niches of $P$. destructans populations on the two continents have not diverged appreciably (Fig. 2).

MOP analyses revealed areas of South America that were not comparable to environments across the calibration regions of North America or Europe (Fig. 3). Environments in Europe and North America showed strict extrapolation risk (i.e. lack of similar environmental combinations) in the Andean region and other South American highlands, and similarity was greatest

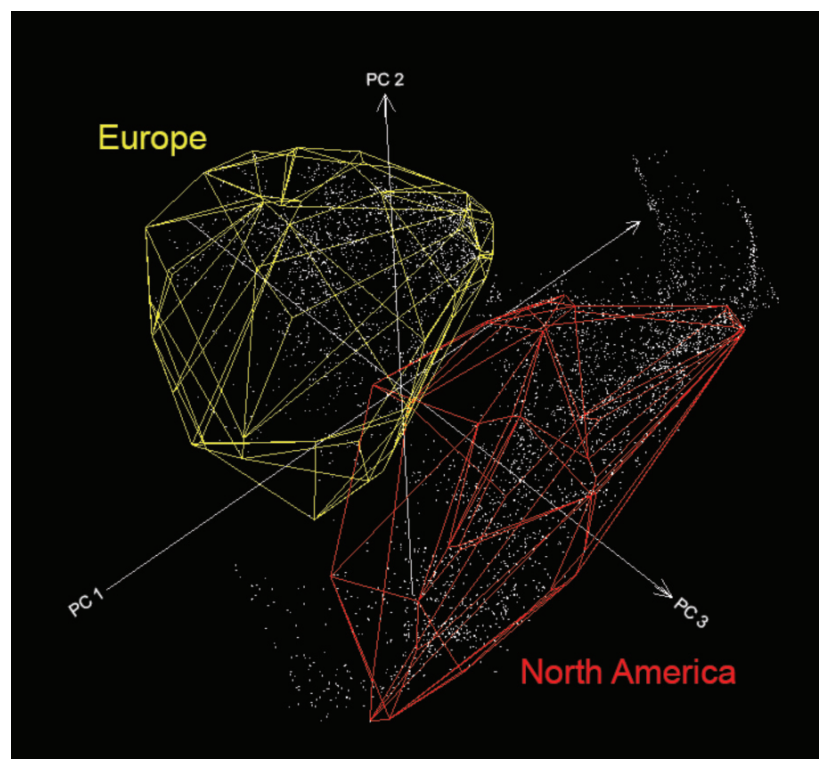

Fig. 2. Estimated P. destructans convex polyhedrons of Maxent ecological niche models for Europe and North America. Delimitation of study areas with potential distribution of $P$. destructans (gray) and actual occurrences (points). Convex polyhedrons estimates calibrated for Europe (yellow) and North America (red) with a threshold of $E=10 \%$ showing minimal overlap between niches. Axes are principal components 1,2 and 3 from 15 bioclimatic layers. Plotted environmental values (white dots). 

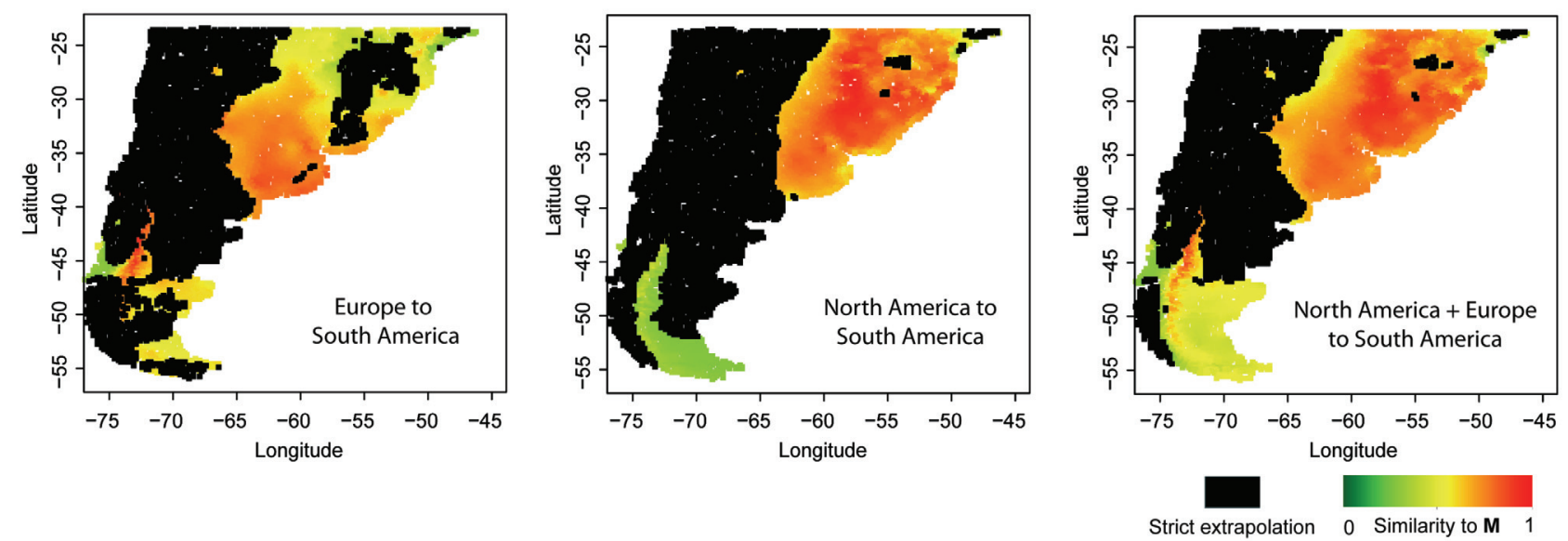

Fig. 3. MOP assessment of environments of areas with different degree of similarity. Areas with different degree of similarity (colours) and strict extrapolation (black) in South America with respect to different model calibration regions (M).

in northeastern Argentina, Uruguay and south of Brazil; Europe showed lower similarity compared to North American environments (Fig. 3). MOP validated some areas identified via transferal of niche models (i.e. environments in suitable areas in South America that correspond to environments in calibration areas of the northern continents).

The geographical areas identified on each continent differed rather markedly when Maxent was used to transfer models without extrapolation or clamping (Fig. 4). When using extrapolation and clamping in Maxent to project models to South America, broader geographical areas were identified, even in environments lacking MOP reference (Figs. 3 and 5). Maxent models calibrated only in Europe and projected to South America identified areas of Chile and northern Argentina (Fig. 5a). On the other hand, Maxent projections from North America fell in eastern areas of South America, including parts of Argentina, Brazil, Chile, Paraguay and Uruguay (Fig. 5b). Ecological niche models calibrated across the two continents pooled were more or less hybrids between the two individual predictions (Fig. 5c).

Transfers of minimum-volume ellipsoids using NicheA yielded results parallel to those of the Maxent models (Figs. 5d, 5e and 5f), although they resembled the MOP maps (Fig. 3) in finding suitable climatic conditions in the Argentinean provinces of Entre Ríos, Buenos Aires, Mendoza, Neuquén, Río Negro and Chubut; in Brazil, Rio Grande do Sul, Santa Catarina and in southern Paraná; in Chile, Libertador Bernardo O Higgins, Maule, Biobio, Araucanía, Los Lagos and small areas in northern Aisén; all regions of Uruguay were found suitable (Fig. 5f).

The study area in South America holds at least 94 bat species, with population richness concentrated in the northern and eastern areas under analysis, particularly in south-eastern Brazil. All putative potential distributional areas for P. destructans in South America indentified by our various modelling manipulations overlapped with the distribution of at least one bat species; in some cases, as many as 57 species (Fig. 4).

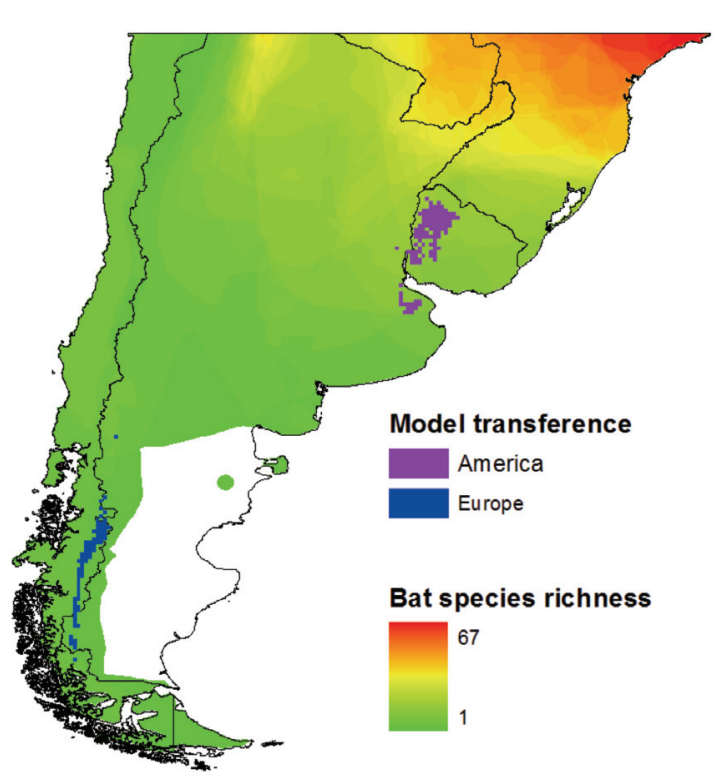

Fig. 4. Suitable areas based on model transfer to South America from niche models calibrated with $P$. destructans occurrences in Europe and North America. Model transfer without extrapolation or clamping that would extend model predictions beyond environmental conditions represented on calibration regions. Background shows bat species richness in areas south of latitude $23.5^{\circ} \mathrm{S}$ in South America (scale of colours). Black lines are country boundaries. White means area with no reports of bats distribution according to the IUCN (see Methods). 

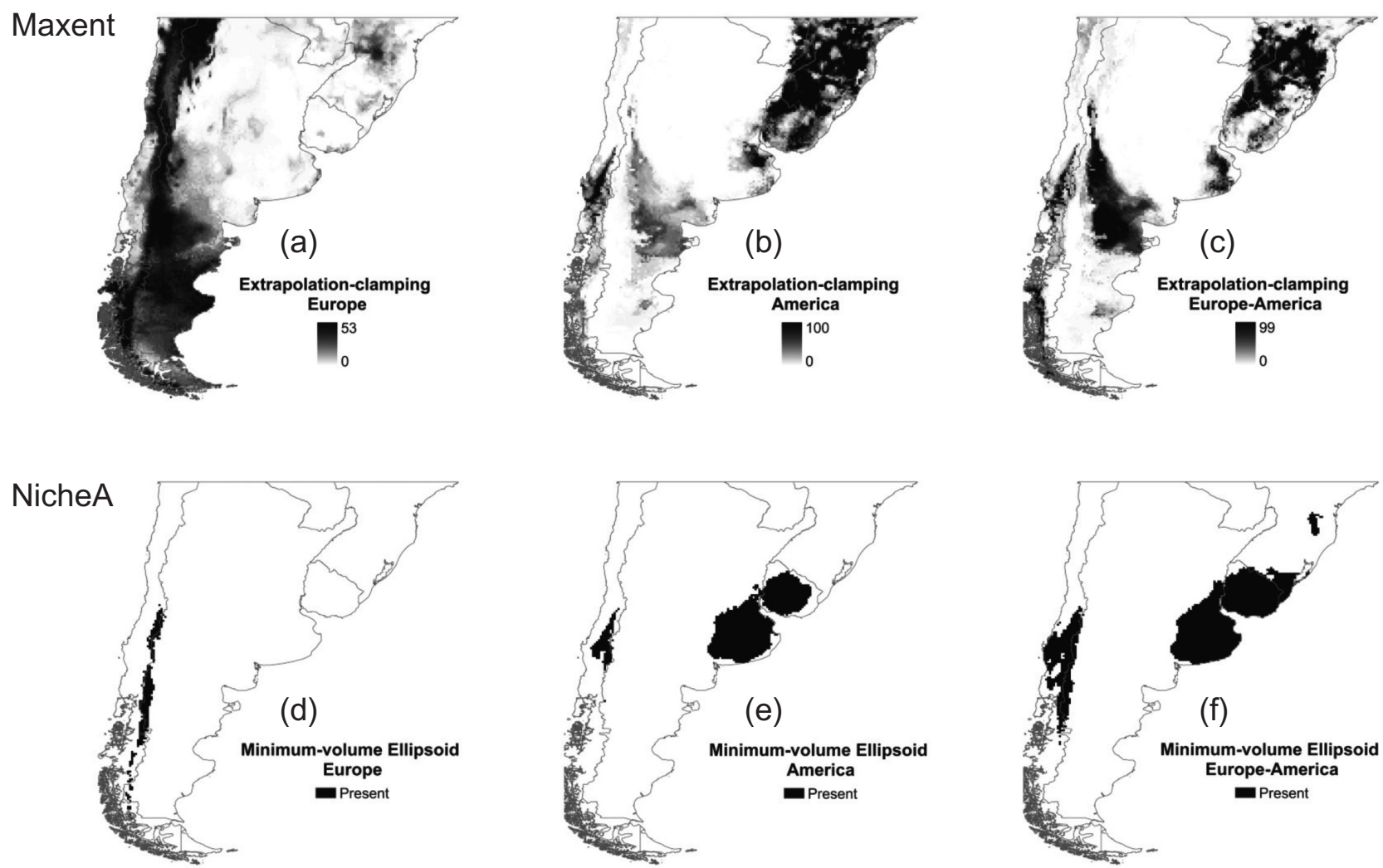

Fig. 5. Transfers of ecological niches to outline potential distribution of $P$. destructans in South America. Top: ecological niche projections using extrapolation and clamping in Maxent from Europe (a), North America (b) and Europe - North America pooled (c) to South America. Dark shading depicts the sum of 100 binary models, ranging from area no predicted by models (white) to areas where binary models concide (black). Bottom: ecological niches from Maxent output projected using a minimum-volume ellipsoid in NicheA for Europe (d), North America (e) and Europe - North America pooled (f). Black represents the binary model outputs.

\section{Discussion}

We found key clues to explain the success of P. destructans as an invasive species in North America. Apparently, this part of the world presents novel climatic combinations not represented within this species' existing, fundamental niche in Europe (Peterson et al., 2011). This was corroborated by the finding that ecological niches of the two populations are more similar in the two continents than can be expected at random, indicating that no real niche differentiation has demonstrably taken place; rather, the "niche differences" are illusory manifestations of climate differences across the two continents. As could be appreciated in NicheA visualisations, different continental study areas differed markedly in size, shape and position in environmental space, such that we considered continents individually and together in generating projections. Consequently, predictions of potential spread based solely on the plausible native range in Europe do not permit rigorous delineation of the niche or the invasive potential of the species; this situation limits the completeness and rigor of model projections to North America (Owens et al., 2013) and led us to calibrate models based on both northern continents for transfer to South America as a best means of mapping invasive potential of $P$. destructans there with least potential for extrapolative situations.

Ecological niche modelling is useful for the understanding of niche dimensions, potential risk and knowledge gaps for WNS spread at the continental level. Although multiple climatic (including microclimatic), behavioural and physiological factors have combined to produce the catastrophic effects of P. destructans on bat populations in North America, previous modelling efforts indicate further potential for the spread of $P$. destructans across the Midwest in the USA in the near future (Maher et al., 2012) with correct anticipation of recent reports (USGS, 2013). Bat species with broad distributions are more likely to overlap and thus be exposed to $P$. destructans-infected sites (Wilder et al., 2011). However, this view must be complemented with better knowledge of environmental conditions and infection routes of the fungus at the finest scales. Cave features, including humidity and temperature ranges, are essential for P. destructans 
establishment (Perry, 2013), while bat movements and roosting characteristics influence the likelihood of infection (Maher et al., 2012) as well as probabilities of spread to other bat colonies (Thogmartin et al., 2012).

Despite their similar latitudinal extents, environments in North America and Europe differ (Fig. 2) with the former offering more diverse climates allowing colonisation of environments not available on the likely, native continent. However, based on our background similarity test results, European and North American P.destructans populations manifest fewer differences with respect to their distributions with respect to climate than expected considering the environments accessible to them (Fig. 2). This suggests that this species has expanded into novel environmental conditions present in North America that were suitable for it given its physiology. Another factor may be the relatively poor documentation of distribution of the species across Europe in the data available to us. More information clearly exists, but the key publication by Puechmaille et al. (2011b) lacks detail on this point. However, taking into account the different environmental spaces used by $P$. destructans across the two continents, we suspect that the species in reality has quite a broad climatic potential. Our potential distribution maps thus help to identify sites for surveillance across the three study areas (Puechmaille et al., 2011a) but may underestimate the species' true potential; we note in particular that our models explicitly do not speak to the species' distributional potential in tropical regions as it has not had access to those conditions anywhere, at least not so far.

P. destructans in North America is clearly not in what can be termed distributional equilibrium, i.e. filling all suitable sites across the broad regions to which it will eventually have access (Peterson, 2003; Peterson et al., 2011; Maher et al., 2012). The situation is rather that $P$. destructans is still spreading across North America, which means that new regions and novel bat taxa will likely be involved as the pathogen spreads. To date, bats hibernating in cave environments are the most affected species (Turner et al., 2011; Perry, 2013), but no research has evaluated susceptibility of infection among neotropical bats. This disease emerged among American bats just a few years ago (Turner et al., 2011), so much uncertainty remains regarding the ecology, epidemiology and potential for host shift.

We explored geographical distributions of putatively suitable areas in South America based on models calibrated across the current distribution of $P$. destructans in the Northern Hemisphere. Although there are strong geographical differences between the European and North American models, transfer of the ecological niche model to temperate South America identified areas suitable for P. destructans (Fig. 4). However the risk areas identified must be considered preliminary at this stage. As expected, broader suitable areas were found when transfers were made with extrapolation allowed (Fig. 5), but it is clear that these projections are only valid to the extent that extrapolated response curves are biologically plausible. Projections based on niche models calibrated on either continent alone appear to underestimate potential areas of invasion in South America for invasion of the fungus because representation of conditions on each continent is still incomplete. Fig. 5 shows the breadth of applicability of these techniques (Jiménez-Valverde et al., 2011). The different algorithms used (i.e. Maxent and NicheA) coincided in the core areas predicted for potential invasion of $P$. destructans (i.e. the Andes in central Chile, northeast Argentina and Uruguay).

WNS transmission has been confirmed among bats in multi-specific roost (Warnecke et al., 2012), but little is known about the possibility of species overcoming the infection and serving as carriers. From a natural perspective, this would be particularly ominous for bat species with long migratory routes, such as Tadarida brasiliensis and Lasiurus cinereus, which migrate $>1,000 \mathrm{~km}$ each year (Constantine, 2003). For example, the known resistance of $L$. cinereus to WNS infections in the epizootic area (Dzal et al., 2011), and the species' long-distance migratory behaviour, offer clear opportunities for P. destructans to spread to South America (see Peterson et al., 2007a).

The geographical distributions of several endemic bat species in South America coincide with areas identified by our projections as suitable for P. destructans, (e.g. L. varius, Myotis chiloensis, Histiotus magellanicus); others overlap partially or have isolated populations within suitable areas (e.g. L. egregious) (IUCN, 2012). Special attention should be paid to species with restricted distributions surrounded by areas for potential invasion of $P$. destructans, such as $H$. alienus and L. ebenus, as well as bat species that roost in high densities (IUCN, 2012). To extend our risk mapping to finer spatial scales, additional variables could be considered, including presence of caves, cave areas and cave characteristics. However, such detailed information has not yet been compiled for Latin America. Indeed, even without fungal infections, little is known about winter bat physiology in southern temperate zones in the Americas: only one single study (on M. chiloensis) has focused on bat hibernation in South America (Bozinovic et al., 1985). That study gives 
clues about species potential for infection in risk areas because WNS affects mainly bats under torpor (Turner et al., 2011) and this species is related to the bat family most affected by WNS (Vespertilionidae). New data will help corroborating and make a better use of these predictions. Finally, our careful management of ecological niche model transfer to novel geographical areas, using Maxent and NicheA in tandem, constitutes a safer approach than allowing niche-modeling algorithms to extrapolate (as is done frequently), even when easily executed, model extrapolation often lacks biological sense.

\section{Acknowledgements}

We thank Bat Conservation International staff, especially Mylea Bayless, Thish Ford and Dave Waldien, for advice and data support. Huijie Qiao provided valuable assistance with NicheA. We thank the University of Kansas Ecological Niche Modeling Group, especially Narayani Barve and Lynnette Dornak. Universidad Andres Bello and Rosi Salazar supported LEE's internship at the University of Kansas. The Biodiversity Informatics Training Curriculum provided training support in several key techniques. The Programa para la Conservación de Murciélagos de Chile encouraged this research.

\section{References}

Badino G, 2004. Cave temperatures and global climatic change. Int J Speleol 33, 103-113.

Barve N, Barve V, Jiménez-Valverde A, Lira-Noriega A, Maher SP, Peterson AT, Soberón J, Villalobos F, 2011. The crucial role of the accessible area in ecological niche modeling and species distribution modeling. Ecol Model 222, 1810-1819.

Blehert DS, Hicks AC, Behr M, Meteyer CU, Berlowski-Zier BM, Buckles EL, Coleman JTH, Darling SR, Gargas A, Niver $\mathrm{R}$ et al., 2009. Bat white-nose syndrome: an emerging fungal pathogen? Science 323, 227.

Bozinovic F, Contreras LC, Rosenmann M, Torres-Mura JC, 1985. Bioenergetics of Myotis chiloensis (Quiroptera: Vespertilionidae). Rev Chil Hist Nat 58, 39-45.

Constantine DG, 2003. Geographic translocation of bats known and potential problems. Emerg Infect Dis 9, 17-21.

Dzal Y, McGuire LP, Veselka N, Fenton MB, 2011. Going, going, gone: the impact of white-nose syndrome on the summer activity of the little brown bat (Myotis lucifugus). Biol Lett 7, 392-394.

Elith J, Kearney M, Phillips SJ, 2010. The art of modelling range-shifting species. Methods Ecol Evol 1, 330-342.

Fenton MB, 2012. Bats and white-nose syndrome. Proc Natl Acad Sci U S A 109, 6794-6795.

Flory AR, Kumar S, Stohlgren TJ, Cryan PM, 2012.
Environmental conditions associated with bat white-nose syndrome mortality in the north-eastern United States. J App Ecol 49, 680-689.

Frick WF, Pollock JF, Hicks AC, Langwig KE, Reynolds DS, Turner GG, Butchkoski CM, Kunz TH, 2010. An emerging disease causes regional population collapse of a common North American bat species. Science 329, 679-682.

Hallam TG, Mccracken GF, 2010. Management of the panzootic white-nose syndrome through culling of bats. Conserv Biol 25, 189-194.

Hijmans RJ, Cameron SE, Parra JL, Jones PG, Jarvis A, 2005. Very high resolution interpolated climate surfaces for global land areas. Int J Climatol 25, 1965-1978.

International Union for Conservation of Nature, 2012. Red list of threatened species. Version 2012.2. Available at: http://www.iucnredlist.org/ (accessed on December 2012).

Jiménez-Valverde A, Peterson AT, Soberón J, Overton JM, Aragón P, Lobo JM, 2011. Use of niche models in invasive species risk assessments. Biol Invasions 13, 2785-2797.

Kunz TH, Braun de Torrez E, Bauer D, Lobova T, Fleming TH, 2011. Ecosystem services provided by bats. Ann NY Acad Sci 1223, 1-38.

Kurta A, Murray SW, 2002. Philopatry and migration of banded Indiana bats (Myotis sodalis) and effects of radio transmitters. J Mammal 83, 585-589.

Langwig KE, Frick WF, Bried JT, Hicks AC, Kunz TH, Kilpatrick AM, 2012. Sociality, density-dependence and microclimates determine the persistence of populations suffering from a novel fungal disease, white-nose syndrome. Biol Lett $15,1050-1057$.

Lorch JM, Meteyer CU, Behr MJ, Boyles JG, Cryan PM, Hicks AC, Ballmann AE, Coleman JTH, Redell DN, Reeder DM et al., 2011. Experimental infection of bats with Geomyces destructans causes white-nose syndrome. Nature 480, 376-378.

Maher SP, Kramer AM, Pulliam JT, Zokan MA, Bowden SE, Barton HD, Magori K, Drake JM, 2012. Spread of white-nose syndrome on a network regulated by geography and climate. Nat Commun 3, 1306.

Martínková N, Bačkor P, Bartonička T, Blažková P, Červený J, Falteisek L, Gaisler J, Hanzal V, Horáček D, Hubálek Z et al., 2010. Increasing incidence of Geomyces destructans fungus in bats from the Czech Republic and Slovakia. PLoS One 5, e13853.

Minnis A, Lindner DL, 2013. Phylogenetic evaluation of Geomyces and allies reveals no close relatives of Pseudogymnoascus destructans, comb. nov., in bat hibernacula of eastern North America. Fungal Biol 117, 638-649.

National Park Service, 2013. White-nose syndrome confirmed in park bats. Department of the Interior, United States of America. Official comunication (Kentucky: Official comunication. January 16).

Owens HL, Campbell LP, Dornak LL, Saupe EE, Barve N, 
Soberón J, Ingenloff KK, Lira-Noriega A, Hensz CM, Myers CE et al., 2013. Constraints on interpretation of ecological niche models by limited environmental ranges on calibration areas. Ecol Model 263, 10-18.

Pearson RG, Raxworthy CJ, Nakamura M, Peterson AT, 2007. Predicting species distributions from small numbers of occurrence records: a test case using cryptic geckos in Madagascar. J Biogeogr 34, 102-117.

Perry RW, 2013. A review of factors affecting cave climates for hibernating bats in temperate North America. Env Rev 39, 28-39.

Peterson AT, 2003. Predicting the geography of species' invasions via ecological niche modeling. Q Rev Biol 78, 419-433.

Peterson AT, 2008. Improving methods for reporting spatial epidemiologic data. Emerg Infect Dis 14, 1335-1336

Peterson AT, Benz BW, Pape M, 2007a. A highly pathogenic H5N1 avian influenza: entry pathways into North America via bird migration. PLoS One 2, e261.

Peterson AT, Papeş M, Eaton M, 2007b. Transferability and model evaluation in ecological niche modeling: a comparison of GARP and Maxent. Ecography 30, 550-560.

Peterson AT, Soberón J, Pearson R, Anderson RP, MartínezMeyer E, Nakamura M, Bastos M, 2011. Ecological niches and geographic distributions. New Jersey, Princeton University Press, 328 pp.

Phillips SJ, Anderson RP, Schapire RE, 2006. Maximum entropy modeling of species geographic distributions. Ecol Model 190, 231-259.

Puechmaille SJ, Frick WF, Kunz TH, Racey PA, Voigt CC, Wibbelt G, Teeling EC, 2011a. White-nose syndrome: is this emerging disease a threat to European bats? Trends Ecol Evol 26, 570-576.

Puechmaille SJ, Verdeyroux P, Fuller H, Gouilh MA, Bekaert M, Teeling EC, 2010. White-nose syndrome fungus (Geomyces destructans) in bat, France. Emerg Infect Dis 16, 290-293.

Puechmaille SJ, Wibbelt G, Korn V, Fuller H, Forget F, Mühldorfer K, Kurth A, Bogdanowicz W, Borel C, Bosch T et al., 2011b. Pan-European distribution of white-nose syndrome fungus (Geomyces destructans) not associated with mass mortality. PLoS One 6, e19167.

Qiao H, Escobar LE, Soberón J, Campbell L, Peterson AT, 2013. NicheA. Version 1.2 beta. Available at: http://biodiversityinformatics-training.org/software-data-sources/nichea/ (accessed on December 2013).

Soberón J, Nakamura M, 2009. Niches and distributional areas: concepts, methods, and assumptions. Proc Natl Acad Sci U S A 106, 19644-19650.

Thogmartin WE, King RA, Szymanski JA, Pruitt L, 2012. Spacetime models for a panzootic in bats, with a focus on the endangered indiana bat. J Wildl Dis 48, 876-887.

Turner GG, Reeder DM, Coleman JTH, 2011. A five-year assessment of martality and geographic spread of white-nose syndrome in North American bats and a look to the future. Bat Res News 52, 13-27.

United States Geological Survey, 2013. White-nose syndrome (WNS) National Wildlife Health Center. Available at: http://www.nwhc.usgs.gov/ (accessed on May 2013).

Warnecke L, Turner JM, Bollinger TK, Lorch JM, Misra V, Cryan PM, Wibbelt G, Blehert DS, Willis CKR, 2012. Inoculation of bats with European Geomyces destructans supports the novel pathogen hypothesis for the origin of whitenose syndrome. Proc Natl Acad Sci U S A 109, 6999-7003.

Warren DL, Glor RE, Turelli M, 2008. Environmental niche equivalency versus conservatism: quantitative approaches to niche evolution. Evolution 62, 2868-2883.

Warren DL, Glor RE Turelli M, 2010. ENMTools: a toolbox for comparative studies of environmental niche models. Ecography 33, 607-611.

Wibbelt G, Kurth A, Hellmann D, Weishaar M, Barlow A, Veith M, Prüger J, Görföl T, Grosche L, Bontadina F et al., 2010. White-nose syndrome fungus (Geomyces destructans) in bats, Europe. Emerg Infect Dis 16, 1237-1243.

Wilder AP, Frick WF, Langwig KE, Kunz TH, 2011. Risk factors associated with mortality from white-nose syndrome among hibernating bat colonies. Biol Lett 7, 950-953. 